\title{
ETNOGRAFÍA DEL CONFLICTO SOCIOCULTURAL EN TORNO A LOS BURROS-TAXI DE MIJAS
}

\section{ETHNOGRAPHY OF THE SOCIO-CULTURAL CONFLICT ABOUT MIJAS DONKEY-TAXIS}

\author{
Huan Porrah Blanko \\ Universidad Pablo de Olavide
}

\section{Resumen}

Con estas páginas se pretende aportar material etnográfico a los debates y circunstancias contextuales relativas a un peculiar conflicto sociocultural en torno a las relaciones entre humanos y animales en el pueblo de Mijas-Miha (Andaluzía, Poniente Mediterráneo), donde la existencia durante seis décadas de un servicio de burros-taxi local para turistas ha desatado estos últimos años una campaña abolicionista por parte de activistas animalistas. Mediante el uso de la metodología etnográfica se origina este artículo fundamentalmente descriptivo y de caso alrededor de las contradicciones de la ideología urbanita-animalista con respecto a las formas de vida y a la cultura campera andaluza. Unos procesos que a veces nos sitúan en la tradicional dialéctica urbano vs. rural, o bien como resultado de un etnocentrismo occidental globalizante con relación a cómo aprehender la naturaleza y lo humano.

Palabras clave: burros taxi, socioecosistema, rural/urbano, antropización, cultura andaluza, animalismo, turismo.

\section{Abstract}

These pages attempt to contribute ethnographic material to the discussions and contextual circumstances of a peculiar sociocultural conflict over the relationship between humans and animals in the village of Mijas-Miha (Andalusia, Western Mediterranean), where the existence over six decades of a local service of Donkey-Taxi for tourists has recenly 
unleashed an abolitionist campaign by animal rights activists. Through the use of ethnographic methodology, this fundamentally descriptive and case-based article is originated around the contradictions of the urban-animalist ideology regarding the ways of life and the Andalusian peasantry culture. Processes which sometimes places us in the urban $v s$. rural traditional dialectic, or as a result of a globalizing Western ethnocentrism in relation to how to apprehend the nature and the human.

Keywords: donkey-Taxis, socio-ecosystem, rural/urban, anthropization, Andalusian culture, animal rights movement, local community based tourism.

\section{INTRODUCCIÓN}

Recientemente se ha reavivado en la sociedad miheña y supralocal el conflicto acerca de la cualidad de la relación entre los animales denominados 'domésticos' con sus 'dueños' humanos, imbricado en un debate sobre la actividad del servicio de burros-taxi en esta localidad algarbeña o de la Costa del Sol (Miha-Mijas, Andaluzía). Para una mirada antropológica dicho conflicto no se deja simplificar fácilmente, mostrando enganches narrativos que nos retrotraen a renovados viejos debates propios de las culturas mediterránea y occidental, recontextualizados en las actuales lecturas de la globalización cultural y económica, así como en debates mayores filosóficos, humanísticos, ideológicos y religiosos presentes en diversos ámbitos de nuestro pasado y que subyacen en los procesos que describimos.

Este artículo pretende, fundamentalmente, una descripción etnográfica del caso de dicho conflicto sociocultural en Miha y alrededores, ya que la residencia de sus principales actores sociales se ubica no sólo en el término de Mijas, sino también en la comarca algarbeña circundante y en las ciudades de Málaga y otras de la Costa del Sol. Utilizando la metodología etnográfica para aproximarnos a cuestiones -aparentementecontradictorias de la ideología urbanita-animalista con respecto a las formas de vida y a la cultura campera andaluza que aún se mantiene en diversos estratos sociales solapados de esta comarca, muy influenciada por el cosmopolitismo costasoleño. Por lo tanto, este trabajo discurre también por la controversia de si dicho debate debiera contextualizarse en las dinámicas propias del cambio cultural o, más bien, haya de contemplarse como consecuencia de un choque entre distintas culturas o maneras de ver el mundo en que vivimos, o maneras de habitarlo, presumible motor asimismo de determinados cambios culturales. Quizás los resultados etnográficos recabados puedan ayudarnos -a nosotr@s o a ulteriores análisis de mayor calado teórico- a comprender e interpretar algunas claves del conflicto en torno al servicio de burros-taxi, uno de los pocos negocios turísticos gestionados por agentes locales de Mijas que quedan. 


\section{APUNTES METODOLÓGICOS}

Unos apuntes nada más para advertir de la metodología que hemos utilizado en esta investigación, a todas luces mejorable y abierta a ulteriores datos, reflexiones y análisis.

Así pues, para etnografiar esta situación hemos tomado como punto de partida el conocimiento previo del contexto local — del que soy vecino desde mi nacimiento-, reconociendo los posibles sesgos personales a la hora de ser lo más objetivo y ecuánime posible al exponer los discursos de los actores sociales e interpretarlos. Mi experiencia personal hunde sus raíces en una educación campesina donde la relación con los denominados animales 'domésticos' o de trabajo ha estado muy presente, además de la experiencia militante en el movimiento socioecologista desde mi adolescencia y el periplo estudiantil por varias ciudades andaluzas y europeas. El primer aspecto obvia la técnica de la observación participante.

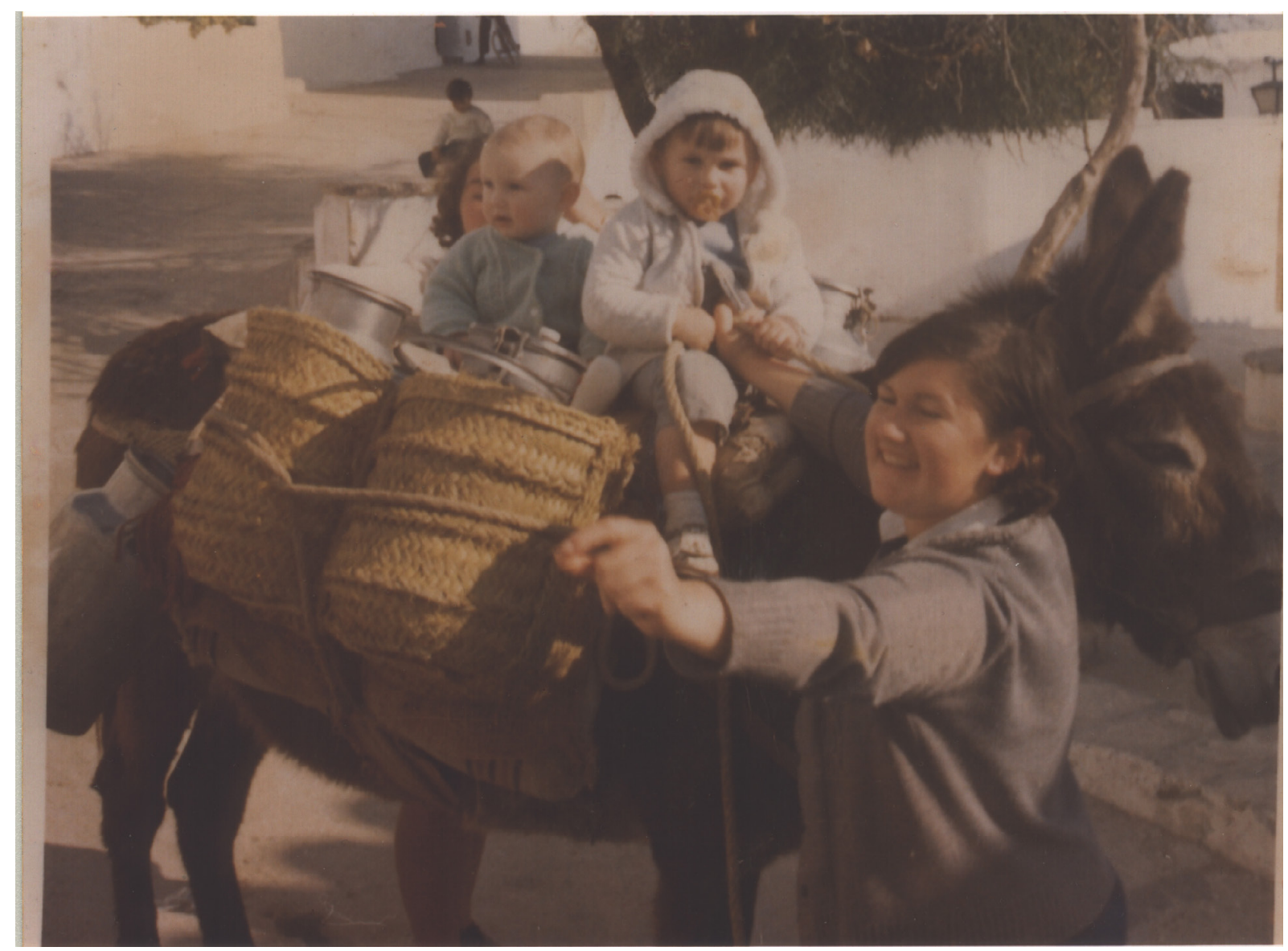

Foto 1: Sesgos personales: Subidos en esta burra estamos mi hermano Migelahe y yo, flanqueados por la lechera y mi madre Izabé Blanko Tamayo (en primer plano).

Para recabar información concreta del conflicto en sí he realizado más de una decena de entrevistas cualitativas personales - algunas con dos informantes- desde diciembre de 2015 hasta febrero de 2016. En el diseño de las entrevistas se ha procurado obtener una tipología de informantes que recoja la diversidad de posturas en este conflicto, 
simplificadas fundamentalmente como trabajadores/as o dueñ@s de animales de trabajo (del pueblo y del campo), animalistas foráneos y local, dueñ@s de mascotas, zoólogos y ecologistas sociales locales. Algunas tipologías concretas, a pesar de estar previstas en el diseño, no me ha sido posible o no me ha dado tiempo suficiente para encontrar informantes. A la hora de transcribir dichas entrevistas se ha tenido en cuenta la lengua de comunicación, dándole a veces reflejo por escrito a los testimonios en andalú o incluso en casteluz ${ }^{1}$, además del castellano. Han sido en total tres mujeres y ocho hombres de distintas edades y clases sociales.

El aporte de materiales para análisis se ha complementado con una búsqueda bibliográfica y documental, además de obtener fotografías y vídeos en torno a las actividades de "trabajo/explotación" (dependiendo del discurso) de animales y humanos.

\section{SURGIMIENTO DEL BURRO-TAXI}

Hemos de situar el origen del burro-taxi en la transformación socioeconómica de la arriería tradicional miheña. De hecho, el de harriéro tradicional es un oficio prácticamente extinto en este territorio, quizás se puede dar algún uso esporádico testimonial en reata'e muloh (hilera de mulas), pero su oficio profesional continuado en el sentido de transportista es prácticamente inexistente. Los arrieros son el origen de los camioneros, personas que con su trabajo transportaban mercancías a través de las sierras, así como, de camino, noticias de los pueblos y cortijos vecinos, chismes varios, inquietudes políticas o productos prohibidos - estraperlo o trahpehlo.

Además de los aspectos más etnohistóricos de la arriería, hemos de referir no obstante la importancia comarcal de una reconversión de la arriería tradicional hacia el transporte de personas en varios pueblos de la Algarbía. Un caso sui generis de dicha reconversión harriéra es el de los burros-taxi de Mijas, llevada a cabo por varias familias de Miha pueblo (aunque también esporádicamente en Coín, Alhaurín el grande, La Cala de Mijas y Granada, entre otros), las cuales pasaron hace varias décadas de acarrear materiales diversos a acarrear turistas, conformándose en uno de los principales atractivos turísticos de la localidad.

Una placa situada junto a la parada de burros-taxi y la oficina de turismo de Miha-

1. Acerca de la transcripción normativizada de los recursos lingüísticos del andalú oral en esta investigación advertimosal@slectores/as que estamos utilizando las Normah Ortográfikah pala Trahkrizión del Andalú (NOTA-Porrah 2009); vid. Porrah (2010a). Al respecto, hemos querido considerar el valor intrínseco de la articulación lingüística propia de vari@s de nuestr@s informantes, es decir, la versión local-comarcal del andalú que utilizan en su modo de expresión habitual. Así pues, buena parte de las expresiones, sustantivos y adjetivos referidos en este trabajo han sido transcritos en andalú —en la variedad dialectal algarbeña del sistema lingüístico andaluz-, en consonancia con esa máxima deontológica que nos exige la mayor fidelidad posible al sentido y forma explícita de los testimonios orales. 
pueblo nos recuerda qué vecino fue el que inició la andadura de esta marca, allá por los comienzos de la década de los sesenta del siglo XX. La placa reza así: "El pueblo de Mijas en agradecimiento a D. Julián Núñez Andreu, precursor del Burro-Taxi. Mijas, 18 de septiembre de 2006".
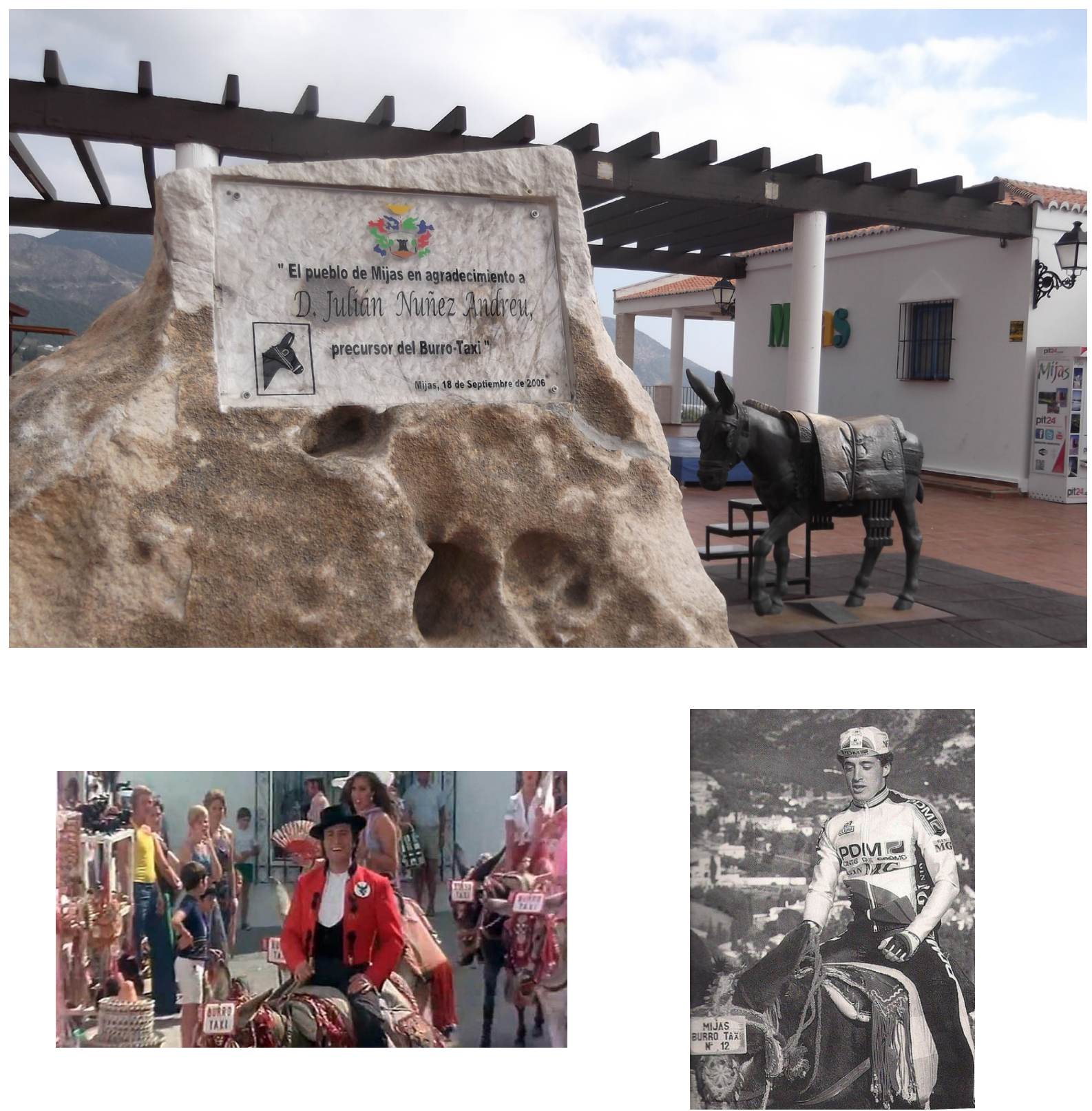

Foto 2: Placa de homenaje al fundador del burro-taxi Julián Núñez Andreu; detrás el llamativo burro de bronce colocado para turistas desde 2013. Abajo.: Personajes retratados en burro-taxi.

Un par de testimonios de arrieros actuales entrevistados nos relatan la transición desde el harriéro tradicional al burro-taxi:

"Como ya avanzó la sociedad -kamióneh, trahtoreh...- entonces el burro se fue quedando atrás y esto se quedaba como una cosa antigua, estaba perdiendo utilidad, 
y entró también el boom turístico; la gente kabía keao ahkí en Miha, burros todavía que venían del campo, po la gente veía esto una cosa típica: una calle de Miha con un burro amarrao a una reja eso llama la atención al extranjero, y por montarse, por hacerse fotos le daban propina grande, que es más de lo que le ganaban to'r día trabahando en la zierra o acarreando leña, o acarreando [arena o piedras]... Entonces, por eso hubo idea de Julián de intentar montar esto, y fue el boom del pueblo, porque Mijas se conoce mundialmente por el burro-taxi”. (S. Torres, harriéro 2).

"Mi padre trabahaba en la zierra, la piedra, las arenas, antes de que hubiera el turismo ahkí, y una vez que ya vino el turismo po puzo loh burro-tazih. Los burros-taxillevarán ahí desde el 63 creo que comenzaron (...) D’aí p’atráh pues se buscaban la vida en el campo, haciendo de harriéro acarreando limones, un poné, de aquí a Laurín, o con la arena y la piedra en la sierra trayéndola a loh kargaeroh de la carretera, porque lo que había era kamionziyoh xikoh namáh". (Harriéro 1, de mayor edad que S. Torres).

\section{EL CONFLICTO (ACTUAL)}

A finales del pasado año 2015 uno de los burros-taxi cae al suelo junto a la parada principal del servicio. Varios arrieros se apresuran a levantarlo, aunque el animal se resiste y se demora la situación, ante la mirada atenta de vari@s turistas que capturan con sus cámaras lo que estaba sucediendo. Uno de los arrieros pierde los nervios y sacude una patada en el hocico del animal. Pese a no tener consecuencias graves fisiológicamente hablando, la secuencia de este maltrato animal inicia su andadura por la red y los mass media escandalizando a quienes las contemplan, que reaccionan con indignación por lo acontecido.

El episodio desencadena un importante antagonismo más o menos coordinado por parte de organizaciones de corte animalista, así como de ciudadan@s anónim@s desde multitud de puntos de la geografía andaluza, mediterránea y europea. Al no ocurrir algo semejante por primera vez en Mijas, y a causa de la creciente sensibilización ciudadana hacia el maltrato animal, el suceso supone la reactivación de protestas por las condiciones de prestación del servicio de burros-taxi, llegándose a plantear abiertamente incluso la abolición de este servicio privado con licencia municipal, tal como reza en bastantes de las pancartas de las varias concentraciones habidas en meses posteriores, así como en las declaraciones de distintos portavoces de los colectivos convocantes.

Los principales actores sociales en este conflicto se materializan en: loh harriéroh, el Ayuntamiento de Mijas, los grupos de presión y los medios de comunicación, cada cual desempeñando un rol específico.

El colectivo no organizado de 8 dueños de licencias de burros-taxi y burros-carro (con unos 52 burros para montarse +17 carritos), así como 12 coches de caballo, además de trabajadores/as asalariad@s, se muestra dispuesto a defender su medio de vida, existiendo 
disparidad de criterios internamente acerca de cómo afrontar el conflicto suscitado, ante lo cual algunos echan de menos contar con una asociación propia que los represente y defienda sus intereses colectivos con una sola voz.

Por su parte, el Ayuntamiento de Mijas es quien gestiona oficialmente las licencias y responsable de regular y controlar la prestación del servicio; para ello cuenta desde el año 2011 con la actual ordenanza reguladora de los servicios tanto de burros-taxi como de coches de caballo. Además, realiza periódicas campañas de propaganda de mejoras en las instalaciones - o intención de mejorarlas- $-\mathrm{y}$ control de las condiciones de calidad de vida del trabajo de los animales. La posición pública de algunos responsables políticos del Consistorio mostrando un calculado equilibrio entre las posturas animalistas y los intereses de los arrieros denota en ocasiones una ambigüedad que suscita a veces el disgusto tanto de unos como de otros.

La presión pública organizada en la actual campaña abolicionista está compuesta, fundamentalmente, por estos colectivos de implantación supralocal sin conexión orgánica oficial: el Colectivo Antitaurino de Málaga, el Partido Animalista Contra el Maltrato Animal (PACMA) y el apoyo de Liberación Animal de Torremolinos. El Colectivo Antitaurino de Málaga se define por boca de sus organizadores - L. de Diego y J.L. Sánchez - como un colectivo animalista nuevo con el fin de "darle la voz a los que no la tienen" a través del activismo de calle, que tiene su nicho original en la movilización antitaurina por varias localidades de la costa malagueña, pero que ha ampliado su radio de acción a otras luchas de corte animalista, como es el caso de los burros-taxi. Al preguntarles por esa deriva desde anti-taurino hacia "anti-burros-taxi" responden:

“Sabes qué día decidimos hacer la primera concentración para el tema de los burros? Fue en la puerta de la plaza de toros de Fuengirola (...) que íbamos a ir a la de Mijas y no pudimos, y dijimos 'tenemos que empezar a mover también el tema de los burros', porque somos un colectivo activista animal". (J.L. Sánchez y L. de Diego).

Por su parte, PACMA es un partido político que con respecto al Colectivo Antitaurino se marcan distancias recíprocas, puesto que la estrategia política fundamental de PACMA en el asunto de los burros-taxi es la vía legal, habiendo iniciado una campaña en base a varios procedimientos de denuncia formal de los cuales están a la espera; pero de momento, declaran, "no estamos convocando las concentraciones, aunque sí apoyamos las concentraciones que hace el Colectivo Antitaurino" (A. González).

El objetivo de ambas organizaciones va más allá de la mejora de las condiciones de trabajo y vida de los burros-taxi, planteando la abolición de este servicio y acabar con el sufrimiento de los asnos. Proponen una transformación radical de este tipo de "prácticas obsoletas" a la nueva sensibilidad animalista occidental que conllevaría reformular 
profundamente el tipo de relaciones entre humanos y animales superando el especismo ${ }^{2}$. La concreción de esa filosofía en nuestro asunto de Mijas se plasma en estas palabras de l@s informantes:

"Queremos cambiar el chip de Mijas, desde ciudad del burro-taxi a ciudad amiga del burro; que ahora se lleva mucho las ciudades amigas de los animales" (A. González).

"No estamos en contra del pueblo de Mijas. Nuestro objetivo es que se acabe con el oficio de arriero [obsoleto en pleno s. XXI], sustituyéndolos por tecnología moderna" (J.L. Sánchez).
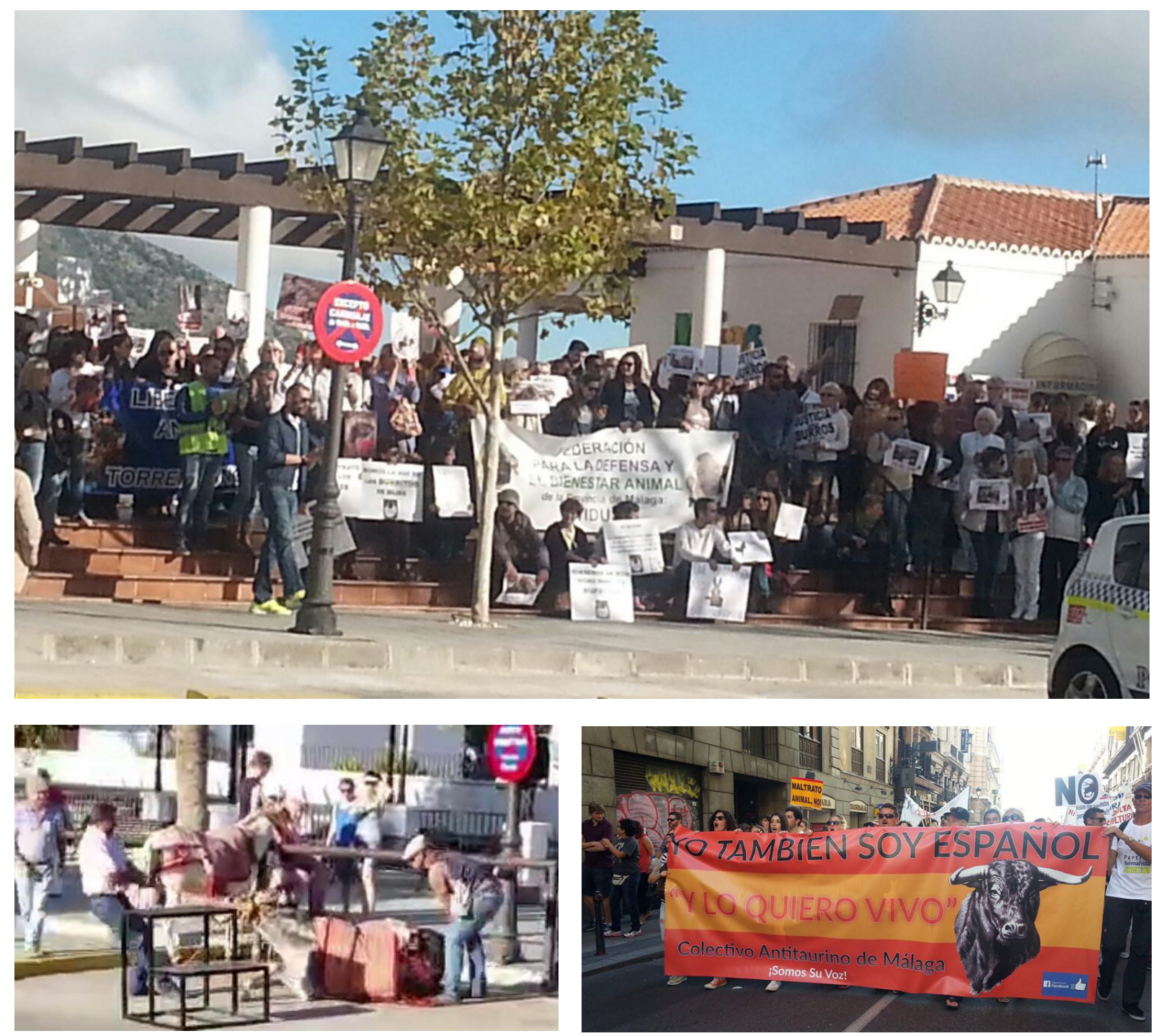

Foto 3: Concentración animalista anti-servicio burros-taxi. Abajo: Imagen origen de última polémica. Dcha.: Iconografía de manifestación del Colectivo Antitaurino en Málaga.

2. Vid. la formulación abstracta y filosófica del concepto 'especismo' en el clásico de P. Singer (1975): Liberación animal. 


\section{LOS DEBATES (DE AHORA - Y DE ANTES-)}

\subsection{Animales de trabajo vs. mascotas}

La primera discusión que ha llamado nuestra atención versa acerca de las cualidades animales. Así, Harriéro 1 afirma que no le gustan demasiado los perros ni los gatos, aunque sí tiene dos caballos para uso recreativo - además de los burros-taxi con su hermano. Dice que algunos de los demás arrieros tienen perros, pero pa kazería, no como mascotas.

"A argunoh animaleh leh farta namáh k'ablà, i zi ablara eh iguá k’una perzona. Argunoh de mih burroh zaben munxo, por lah tardeh aora kon er frío me ze kean mirando i me dizen "Ya ehtá bien, yébame ya d'ahkí". Er trato eh ehtà kon eyoh pegao; zi no ehtáh a la bera d'eyoh po no loh konozeh, ezo eh normá. Zi ehtáh a zu bera zabeh mah u menoh de la pata ke kohea ka uno; er trato ba arreglao a la naturaleza [indibiduá] de ka animá: guenoh i maloh (...) Loh anti-burroh no konozen a loh animaleh, zi loh konozieran po no protehtarían (...) Loh animaleh ke tienen zon un perro en zu kaza, i par trato un burro i un perro zon mu diferenteh, par trato no eh iguá, er maneho eh mah bronko". (Harriéro 1).

Esta opinión contrasta con, por ejemplo, la de A. González —veterinario de ciudad, animalista de PACMA - quien considera genéricamente cómo hay que tratar a los burros: "Con respeto, como se trata a un perro, como el que tiene un perro y lo quiere (...) Caricias, cariños y buenos cuidados".

El animalista antitaurino J.L. Sánchez manifiesta que no quiere diferenciar entre mascotas animales y de granja: "Para mí lo mismo es un cerdo que es un gato". Su compañera antitaurina L. de Diego dice tener perros y gatos en su casa de Málaga, y que "cuando era jovencita, me da pena decirlo, iba a una escuela de hípica en Madrid y tenía un caballo; ahora me parece inconcebible pensar que he montado a caballo, pero bueno, las cosas van cambiando”. Compara la situación de dichos caballos de hípica con los burros-taxi:

“(...) No tiene nada que ver cómo están; los caballos que yo montaba, los montaba yo, que pesaba $20 \mathrm{kgs}$., y todo el día los bañaban, los paseaban, corrían. No hay comparación con estos burros que están todo el día con gente encima, y atados; los caballos de hípica están sueltos".

Al plantearle en la entrevista posibles soluciones técnicas a las situaciones concretas que comentan, L. de Diego cierra el tema sentenciando: "Que no, que no tienen por qué estar montando turistas para arriba y para abajo, lo animales no son para nuestro uso". Seguidamente les pregunto qué ocurre con los perros, a lo que contesta: "No vayas a comparar el perro que yo tengo en mi casa, en mi cama, tapado con la manta, con el burro de Mijas". Su compañero J.L. Sánchez completa la aserción explicando que él se dedica a trabajar en su casa para cuidar a sus animales, traídos-rescatados de la calle: 
"Para disfrute mío no están, sino para que vivan lo mejor posible, dado que yo trabajo y me lo puedo permitir; aunque eso no me da derecho a nada sobre ellos".

F. Criado - mujer miheña de 70 años dueña de mascota - nos decía que

"er burriko a zío ziempre de trabaho, no a zío una mahkota. Loh toroh eh mu diferente a loh burroh; yo no ehtoi en kontra ni a fabó de loh toroh, yo lo k'ehtoi en kontra d'ezo ke matan loh toroh kon lanzah (...) Ziempre an zio lah behtiah par trabaho: loh kabayoh loh tenían loh zeñoritoh, loh muloh i loh burrikoh loh tenían lah perzonah pa trabahà en loh kampoh".

Finalmente, el ecologista social miheño J. Alarcón nos analizó el concepto de mascota explicando que ha evolucionado y no corresponde el de hoy día con el que había antes, y que está muy en relación con el contraste entre las culturas urbana y campesina: "Yo zufría munxo kuando mataban a un xibo, o inkluzo zi una kabra bieha ze moría (...), o zi ze tienen ke yebà una gayina, yo zufría kon ezo, pero er konzehto no eh duna mahkota". Querer a un animal, dice, dependerá de cómo sea la condición de la persona, por eso tampoco le gusta el concepto de 'animal de compañía', habiéndose criado él con animales de campo e incluso con algunos animales brabíoh, como el zorro.

\subsection{Trato ético vs. Maltrato}

Otro debate nos sitúa en el modo de relación mismo de los seres humanos con los demás animales, filtrado desde la percepción propia de las distintas sensibilidades humanas. Entre nuestr@s informantes, a l@s animalistas antitaurin@s L. de Diego y J.L. Sánchez de los burros-taxi les preocupa "el maltrato al que son sometidos diariamente y de forma continuada", y lo explayan del siguiente modo:

"Es que ya simplemente por estar atados todo el día con una cuerda de $2 \mathrm{cms}$., que no se pueden rascar, todo el día ahí atados y que vayan paseando gente parriba y p'abajo a $40^{\circ} \mathrm{C}$ en verano a gordos y así, pues hemos visto gente de $100 \mathrm{kgs}$. encima de los burros, es un maltrato en toda regla. Hemos visto fotografías de cómo están sometidos... cómo se maltratan; el famoso vídeo ese que ha visto todo el mundo, los arrieros pegándole patadas a un burro, en la boca (...) El tema no es cuando viene una persona obesa lo montamos en otra cosa [o burro], ¡no!, tú estás manifiestamente creando un maltrato sobre ese animal igualmente, da igual que sea uno que tenga más capacidad para llevar peso; eso es así, impepinable (...) El simple hecho de que a los animales se les someta a eso, que se convierta en un trabajo para ellos, eso ya es un maltrato, cuando es para que ellos [los turistas] se diviertan. [¿Y los caballos?, pregunto.] Te hablo como vegano -J.L. Sánchez-, tan malo es una cosa como tan mala es otra. El maltrato parte de que tú le das un tipo de vida al animal que no es el tipo de vida que debería llevar. Entiendo que tú tengas un burro que te ayude a ir al campo, que eso ya no se utiliza prácticamente... Estamos hablando que es por un 
tema laboral, no un tema de 'vamos a divertir a la gente, vamos a ganar dinero' a través de ese maltrato. [Pregunto de nuevo al hilo: ¿Maltrato en concreto es que están amarrados corto y que trabajan, no?] No, no; que cogen peso continuamente de unas cantidades que... Pueden aguantar $150 \mathrm{kgs}$. de peso, ¿pero durante todo el día pueden aguantar $150 \mathrm{kgs}$. de peso? [Los arrieros dicen que son sólo 15 minutos al día.] Las columnas de los burros no están así por 15 minutos al día”.

Más adelante les preguntamos si les parece lo mismo el maltrato hacia los toros en las corridas o en el Toro de la Vega que hacia los burros-taxi, respondiendo:

"Me parece exactamente lo mismo, es el sufrimiento de un animal: el toro al fin y al cabo muere en 20 minutos, animalito, y al burro lo tienen 30 o 20 años atados así, cargando gente para que luego acabe en un matadero... pues no sé qué decirte ( $L$. de Diego). Para mí el problema radica en el maltrato, y da igual que el maltrato se produzca en 20 min. o 1 hora o durante 30 años; y al final vamos a lo mismo: maltrato es violencia contra un ser inferior". (J.L. Sánchez).

El otro animalista que se autocalifica como 'radical', el veterinario A. González, explica el origen de la denuncia de PACMA:

"Vi las condiciones de los burros cuando no están trabajando y a raíz de ahí dije de denunciar la situación (...), que duermen atados, con correas así... Cuando vi eso lo puse en conocimiento de mis compañeros, grabé vídeos... es que no pueden estar así. También porque por parte de PACMA llevamos tiempo recibiendo quejas de gente del pueblo de a ver si hacemos algo por los burros. Ha coincidido lo que yo he visto con la queja, para decidir hacer una campaña pues contra esto. No se pueden tumbar, no pueden tener vida sociable, no pueden relacionarse, no pueden estar libres sueltos ni un minuto de su vida, nunca, nunca. Así tratados y están trabajando, y eso no puede ser".

Asimismo, preguntamos a A. González por si les parece distinto el maltrato hacia los toros en las corridas o en el Toro de la Vega que hacia los burros-taxi, a lo que responde:

"Sí es lo mismo; luchar por los derechos animales, sea en espectáculo que da muerte o en condiciones de vida que no son éticas". ¿Tener perros encerrados sería maltrato?, pregunto. "Hay que verlos caso por caso. También estamos en contra de los coches de caballo de Mijas", aunque reconoce no haber constatado las condiciones de vida de los caballos fuera del trabajo. ¿Y los caballos que se utilizan en las romerías?, continúo. "Caso por caso", responde. No se plantea quitarlos totalmente en las romerías "porque no es un trabajo continuado de todos los días"; si los burros no trabajaran todos los días se mostraría más transigente, y compara los de Mijas con los del Tívoli (Benalmádena), donde "hay burros que es que no tiene nada que ver". 
Otro animalista de ciudad, aunque autodefinido como 'no-radical', opina que no ve mal "que se le dé una salida al burro, que ha sido un animal de trabajo" (A. Paz). Plantea que se debe "regir y medir bien el servicio", reconociendo que en sus años de conocimiento de los burros-taxi "han mejorado mucho las instalaciones y demás con respecto a como estaba antes". Puntualiza algunas cuestiones más, como que

"en ehta zona [de l’Argarbía Kohta] el animá de trabaho muxah bezeh z'a kombertío en mahkota. En l'Azarkía er burro zige ziendo burro, i le dan er trato komo animá de trabaho. Zí eh berdá ke kuando yo e bihto a loh animaleh trabahando i ezo, nunka e bihto k'aya un martrato o ehté mar kuidao".

Harriéro 1 reconoce autocríticamente que "la [famoza] patá ehtá mar pegá: ¡lah kozah klarah!", si bien precisa que lo de arrastrarlo es normal, sino no se levanta del suelo. Sostiene que "se sabe cuándo hay maltrato de verdad". Asimismo, diferencia entre el caballo y el burro, siendo aquél más inteligente1 y concluye que "er ke l'exa de komè to loh díah eh er ke konoze al animá". Dice no estar conforme con lo que hacen del Toro de la Vega _"un asesinato"-, y explica que "aquí no se mata a los burros ni nada de eso; a los burros les pasan cosas al igual que les ocurre a nosotros las personas"3.

"Pa pazearze eh er martrato ke yeba er burro namáh (...) No berán a munxa hente de martratà a un burro a patáh u azín, zeguro ke no. Pazearze en un kabayo zería tambié er mihmo martrato, en koxe’e kabayo, totarmente eh iguá”. (Harriéro 1).

El también arriero S. Torres declara que "hay que tratar bien a los animales" y defiende que "los burros aquí están bien atendidos, bien alimentados", asegurando que no tienen los problemas que dicen quienes protestan, porque "son mentiras que están diciendo porque les conviene la polémica de los burros-taxi”. Sobre la relación con los animales realiza el siguiente razonamiento:

"Lah perzonah tienen zu zitio i loh animaleh tienen otro; tú tieneh ke rehpetà a loh animaleh $i$ tieneh ke rehpetà a lah perzonah (...) Pero ai perzonah ke rehpetan mah a

3. En el contexto de la entrevista Harriéro 1 está aludiendo a un suceso que le ha afectado directa y gravemente en Miha-pueblo. Afirma que una vecina (nativa) llamó a la policía porque creía que él había matado de una paliza - sin haberlo presenciado ella en persona ni tener prueba alguna- a uno de sus burros que se le murió en la calle junto a la cuadra, a causa de un infarto según la autopsia que más tarde le hicieron. La noticia se convirtió en un bulo cada vez mayor y circuló por las redes in crescendo, llegándose a oír que lo había matado a martillazos en la cabeza. Harriéro 1 nos contó que le extraña todo, ya que asegura que él es el último interesado en matar a ninguno de sus burros: "porke me kuehta a mí er dinero (arreóe 1.000€), i porke yo por un burro miro mah ke zi fuera una perzona, te lo digo de korazón (...) De to er mar trago me tiré treh díah komiendo i degorbiendo; tenía un núo en el ehtómago penzando en ezo namáh”. 
loh animaleh ka lah perzonah, i ai perzonah k'a loh animaleh no loh rehpetan i no loh kieren ni bè, kuahkié animá le da ahko. Ezo ba en el indibiduo". (S. Torres).

Acerca de las quejas de que los burros están amarrados todo el tiempo, S. Torres explica que es "para evitar que se hagan daño entre ellos y para que cada burro se coma su pienso, porque si come de más le da un cólico o se congestiona, y porque son jerárquicos como los perros, por lo que el burro más cobarde no come". También hay establecido un proceso de rotaciones entre los 69 burros, por lo que a él le toca "una vez al día o cada dos días, en invierno una vez por semana (...); el turno corre como en los taxis normales". Además, asegura, "no están amarrados todo el tiempo": en el cambio de turno se quedan un rato sueltos, así como cuando entran en la cuadra, "que van sueltos y se revuelcan". De igual manera señala que suele trabajar sólo con la mitad de sus burros, menos en verano, y que algunos de esos sobreros los tiene amarrados largo en un campo de Zuniya. Sobre el exceso de carga asegura que el 70\% de los clientes son niñ@s y de poco peso, que utiliza los burros más fuertes para "pesos pesados" y que los más pesados los monta en burro-carro, siendo lo corriente que al año vayan no más de tres personas de 150 kgs. Explica que llevan "60 años trabajando de cara al público", y que en caso de que los burros estuvieran "realmente maltratados, esclavizados o malnutridos la gente del pueblo se echaría encima, además de que habría 400.000 denuncias de los propios turistas que vienen a verlos y a montarse (...) pues solo hay la del PACMA". Por último, S. Torres da otro motivo contra el maltrato de los burros, ya que desde el punto de vista del manejo "un burriko martratao no eh fiáble", y la mayoría de sus clientes son infantes.

El ecologista social miheño J. Alarcón, que también se define como defensor de los derechos de los animales, advierte durante la entrevista de la banalización del concepto de maltrato, espetando que "a bè zi moh bamoh a borbè aora mah papihtah kér Papa". Ante nuestra pregunta de si cualquier cosa puede considerarse maltrato, realiza estas consideraciones:

"En derexoh de loh animaleh... la linia eh mu fina entr'una mentalidá i otra. Ehtá la ke progrezibamente tenemoh ke i abanzando de ke nozotroh no zomoh el orihen del uniberzo, ke no zomoh er zentro de to -antropozentrihmo, ehpezihmo- (...) ke plantea ke no podemoh krià animaleh zarbaheh pa kital-le la pié, pero podemoh penzà 'I una baka ke la kriamoh pa lexe i komía, kuando muera, ¿eza pié no ze puede utilizà pa kuero?' Entonze, ¿por ké no? Tenemoh ke buhkà dónde ehtá la frontera (...) En er mobimiento der mundo de la relazión kon loh animaleh ai'hkien lanza la piedra mu lehoh mu lehoh - a la mehón en 500 añoh la relazión zea ke ni ze koma animaleh, o zea er zè mah artifiziá der mundo, depende de kómo ze koha. En lo ekolóhiko tambié kreemoh ken beh d'animaleh de graha intenziba debería de kambiarze por una ehtenziba, k’ademáh, er tiempo ke biba, ehté en ezoh bohkeh komiendo beyotah i pahto; ke ba tenè una bida mehón, anke dihpuéh tenga ke morì palimentarze (...) 
[¿Eh martrato zubirze en un burro?, pregunto.] Eza pohtura tendría ke zè iguá kon er kabayo, ke z’utiliza pa montà una perzona pa dà guertah. Er tú zubirte en lo artóe un animá no puede zè martrato, joho!, un animá ke dehd'aze mileh de añoh eh pa montarze o pa zubil-le pezo - porke zon animaleh mu fuerteh i zirben pa ezo, karkulando loh pezoh (...)_; er martrato zería er gorpeal-lo, er no dal-le de komè, metel-le mah karga de lo pozible, tambié puede zè tenel-lo amarrao ar zo pegao aí muxah z'orah... To ezo ze puede zoluzionà, pero martrato no puede zè zubirte en lo arto (...) Aht'aí podemoh yegà a un ekilibrio, zi zobrepazamoh eze ekilibrio, podría zè ke konzideráramoh ke martrato zea tenè tu perro enkariñao a ti... podría zè un martrato zikolóhiko a eze animá”. (J. Alarcón).

\subsection{1. ¿Castración es maltrato?}

Un debate específico sucedáneo del maltrato - que se muestra paradigmático de las distintas posturas- ha emergido también en las entrevistas, acerca de si la técnica de castración de animales para adecuarlos a determinados contextos relacionales controlados por los humanos puede considerarse ético o no.

$\mathrm{Al}$ respecto de loh burrikoh enteroh, el veterinario animalista A. González propone "que los castren para que puedan estar sueltos". Cuando le pregunto si esa medida no le resulta "inhumana" explica lo siguiente:

"A ver, los burros son animales que viven en colonias, son sociables, y si el castrarlos, igual que una mascota, conlleva que el animal pueda estar suelto no me parece inhumano. [¿Por ké ai ke kahtrà a lah mahkotah?, le cuestiono]. Para que no haya superpoblación de perros, que acaban siendo perros abandonados... el celo, dos veces al año, es un problema. Lo castras y el animal no sabe que lo han castrado, porque no tiene el trauma que tiene un humano de 'me han quitado los huevos'; los animales se duermen, se despiertan y simplemente no procrean, ya está. [¿Zabemoh zi ze ziente iguá dihpuéhe kahtral-lo?] Sí, se sienten igual, porque ellos no son conscientes del hecho 'me han castrado' (...) Castro muchos perros, incluso los míos, y no les pasa nada, simplemente que tienen menos ganas de estar con perras. Los arrieros no quieren castrar a los burros porque piensan que van a trabajar menos; sin embargo se castran $y$ trabajan exactamente igual. [¿Eh lo mihmo pa loh burroh ke pa loh perroh?] Sí, simplemente que no van a buscar esa territorialidad con otros machos para ser ellos el dominante, porque no se van a morder entre ellos... Se pelean porque el más fuerte es el que está con las hembras. En el Refugio del Burrito los tienen así; se acercan, se vienen a jugar contigo, superfelices, muy bien. [¿Kuá eh er problema de ke ze peleen loh maxoh?] Se hacen mordeduras, se matan, no les puedes dejar encerrados solos porque se harán mordeduras, y luego los ve la gente y van a pensar que se lo han hecho los arrieros. [Le planteo qué piensa de otra solución, como la ligadura de trompas para burras o la vasectomía de burros]. Sí se puede hacer, pero se van a pelear; van 
a tener que estar solos, el burro salvaje está en manadas, en grupos”. (A. González). El animalista reconvertido de 'radical' a 'no-radical', pedagogo y ecologista social, A. Paz, discrepa con A. González preguntándose “¿ahta ké punto la kahtrazión no eh mah martrato [k'er ke ze peleen]?”, y plantea como alternativa no cruenta el uso de un buen bozal, porque opina: "kahtrà lo beo peó". De otra parte, Harriéro 1 también disiente de la castración, asegurando que "loh burrikoh kapaoh ze ponen mah nobleh, pero z'azuhtan munxo", con el peligro que conlleva para el transporte de jinetes inexpert@s, además de no simpatizar con esa cirugía para sus burros, reprobándole a sus promotores: “iGueno, po kaparoh uhtedeh a bè zi zoh guhta!"

De similar opinión es S. Torres (Harriéro 2), quien me cuenta que el Refugio del Burrito les recomendó castrarlos, ante lo cual realiza estas reflexiones:

“Un burro kapón zíbale parkampo, porkehtá en zuámbito [de trankilidá]. Erproblema eh ke nohotroh trabahamoh en pleno kahko urbano i er burro kapón z'azuhta de to loh ruíoh, z’ehpanta... i un burriko entero no. Yo a tenío burroh kaponeh i er problema eh ke tiran a la hente (...) [Hueraparte, konzidera ke] kapà eh martrato tambié. Zi fuera a lah perzonah 'iehto eh kruerdá!, ehto ai ke kortal-le er kueyo ar ke lo arga dixo'; no, no, eh ke tú bah a trabahà en tu ofizina kon muhereh i ombreh, i pa ke tú no le piropeeh a la muhé i le digah ké guena ehtá, te bamoh a kortà loh gueboh, pa ke tú ehtéh trankilo i la muhé ehté trankila. Ezo eh lo ke paza ahkí; zi bamoh a zè ekitatiboh lo bamoh a zè pa lah perzonah i pa loh animaleh" (S. Torres).

\subsection{Campo+pueblo vs. Ciudad; "silvestrismo" vs. progreso}

Otra cuestión que subyace a este conflicto se ciñe al viejo-nuevo contraste entre las culturas urbana y rural, dialéctica a la que se ha enrocado otro par de opuestos "paralelos" en forma de progreso versus "silvestrismo" - eufemismo de salvajismo para algun@ssuspuestamente asociados a sendos territorios y que también se asocian con la distinta cualidad en el modo de relación con la naturaleza por parte de los humanos. Al respecto, el antropólogo A. del Campo ha planteado:

"El burro, dado el carácter de animal secularmente maltratado, indefenso y pacífico, parece despertar en los últimos años una inusitada solidaridad en una sociedad que mira con recelo al hombre de campo que aún mantiene algún burro tal y como lo hicieron sus antepasados" (Del Campo, 2012: 486).

El animalista urbano A. González ha trasladado así sus intenciones: "Queremos cambiar el chip de Mijas, desde ciudad del burro-taxi a ciudad amiga del burro; que ahora se lleva mucho las ciudades amigas de los animales"; obviando las resistencias identitarias miheñas a que se les considere una ciudad en lugar de un pueblo, además de presuponer que en la actualidad Miha sea un lugar "enemigo" del burro. Tampoco comparte que sea necesario ya el trabajo de estos animales: "Antiguamente era un transporte, pero hoy en 
día no tiene sentido que estén (...) Hay métodos alternativos de transporte: uno de estos de pedales, un carro eléctrico...”. Igualmente, J.L. Sánchez sostiene que "estamos en el año 2016 y hay cosas que ya no deberían entrar en nuestra sociedad", y estima que existen alternativas al paseo en burro para los turistas, que es posible otras maneras especiales de ver "el bonito pueblo de Mijas sin tener que utilizar animales", mediante el uso, por ejemplo, de "un tren eléctrico".

Otro aspecto de contraste se circunscribe al distinto nivel de vinculación con la tierra entre los ciudadanos y los campesinos-pueblerinos. Curiosamente, la gran mayoría de nuestr@s informantes nativ@s de Miha _ya sean arrieros, dueña de mascota, cabrero o ecologistas - son quienes se muestran más díscolos con la eliminación total del servicio de burros-taxi, a pesar de su heterogeneidad de perspectivas. Uno de ellos, Cabrero, lleva prácticamente sus 58 años con una vinculación casi continuada con su partío rural de nacimiento y residencia. De joven Cabrero acarreaba leche al pueblo con la burra de su familia; ahora él tiene una burra ${ }^{4}$ en su campo que utiliza para sacar las aceitunas de los lugares más inaccesibles y a veces para llevar aparehoh y avituallamiento cuando recorre los cerros y cañadas del municipio con el rebaño de ovejas o de cabras que pastorea. Al preguntarle por la intención animalista de abolir — kità - los burros-taxi, él y su familia campesina se indignan considerando fundamentalmente de manera pragmática que, al oponerse, los animalistas mismos "ban a tenè la kurpa de ke dezaparehkan loh burroh... lo ke ban a hazè eh peó, porker tío ke tenga animaleh ¿ká ba hazè?, ¿namáh kexal-le de komè?... po a kital-loh d'ermedio; lo ke ban a hazè eh matal-loh [pa kahne]".

$\mathrm{El}$ joven S. Torres también cree que los abolicionistas son "hente’e ziudá, i k’er 90-95\% no an bihto un burro en zu bía... i ke tienen er perrito metío en la kaza". Según este informante, se trata de "gente que viene, se manifiestan y se van", y las firmas que recogen son de "gente de Madrid, de Barcelona, que nunca ha venido aquí". Torres devuelve indignado el prejuicio etic que presupone tienen en las ciudades hacia loh harriéroh miheñoh: "Ahkí zomoh kabehnikolah, ahkí matamoh loh burroh... loh hazemoh morziya kuando yega Nabidá, u... ¡yo ké zé lo ke pienzan!"

El conocimiento de los animales a través del trato directo continuado provoca a veces una mayor simbiosis entre campesin@s y sus animales, desdibujando los tópicos límites entre "hombre y naturaleza", según sean más o menos indígenas, según sean más parte

4. Es conocida la separación territorial entre burras y burros en el municipio miheño, siendo el pueblo espacio reservado para los burros machos y el campo para las burras, ocurriendo que hacia los años ochenta una normativa municipal impedía la entrada de burras al casco histórico, obligando a 1@s campesin@s a dejarlas atadas en la entrada del pueblo. Al parecer la actividad de burros-taxi capitalizaba el espacio urbano para los machos, que se ponen muy alterados si detectan la presencia de una burra, especialmente en periodo de celo. 
integrante del socioecosistema. No habituados de manera espontánea al trato comercial con los turistas, Caballista-cochera, de origen foráneo y semi-urbana, nos transmite la sensación de que en su rusticidad "parece que los arrieros son algo antipáticos con los clientes". Asimismo, considera que el trato hacia los burros no es "un problema tan grave como lo están poniendo"; sí que ha visto que los burros estaban un poco sucios, pero que ahora están mucho mejor.

La ubicación de cuadras en el interior del pueblo es otro punto de discordia en esa marea que va llenando de 'progreso' lo rural que queda de Miha-pueblo. De las muchas que había, sólo quedan dos cuadras de burros con salida a calles interiores - en el perímetro del pueblo hay otras dos más-, una expulsión progresiva que genera, por ejemplo, el siguiente comentario en Harriéro 1: "La hente [de Miha] ehtá ya mah zeñorita, ya no'hkieren loh zanimaleh en er pueblo... kitaron lah kabrah i ya mihmo zerán loh burroh", situación que contrasta, según dice, con otros pueblos del interior de Andaluzía, que aún son como era Miha.

El ecologista J. Alarcón resalta que "los indígenas cazan animales y les tienen respeto", siendo su relación con el animal "muy diferente a la nuestra occidental", algo similar a "la del campesino nuestro". Alarcón plantea que campesinos y ganaderos son los que tienen que jugar con los dos mundos: "er mundo de anteh -en er kél animá eh un elemento mah-, i tiene ke hugà kon er rehpeto azia eze animá... Dehpuéh, el urbano eh er ke puede lanzà la piedra mu lehoh porke no tiene una relazión tan direhta por nezezidadeh. Inebitablemente ai ke buhkà un ekilibrio entrezoh doh mundoh", aludiendo finalmente a la responsabilidad de la mentalidad capitalista y de las ciudades.

La entrevista con A. Paz - urbanita ecologista evolucionado desde el animalismo radical al no-radical- aporta otra perspectiva interesante al preguntarle por cuál cree que es el origen de 1@s abolicionistas:

Loh englobaría mah en el entohno de ziudá. Por mi ehperienzia i porke yo e kometío loh mihmoh erroreh ahta ke no me informao de bè a loh animaleh de graha, de trabaho, ehz. kon un parámetro; i kuando e kombibio kon perzonah k'an bibio d'eze trabaho, biendo er día a día kon loh animaleh, te dah kuenta de kai muxah ideah ke zon farzah del entendè kómo tiene k’ehtà un animá. Er problema eh k'emoh kerío zè i kreernoh mehoreh zin zabè kómo. Tú ereh una perzona, no eza ehpezie animá, eza ehpezie animá komo tú ehtáh diziendo no eh [un poné, er perro]. Le damoh una bizión antropomórfika, i ezo no puede zè. tenemoh ke zabè k’ehtamoh tratando kon tal ehpezie, porke zinó yo kreo ke berdaderamente ze le haze mah daño ke benefizio. I er problema eh kén la ziudá ezo no żehperimenta, porker kontahto ke nozotroh [urbanitah] tenemoh kon loh animaleh eh mínimo, i er kontahto ke ze le da, por ehemplo, a loh perroh de ziudá eh dihtinto ar de loh perroh der kampo (...) Ai kéehtudià etolohía pa zabè rearmente kéh un martrato (A. Paz). 


\subsection{Extinción vs. refugios-“reserva”}

Ha aparecido también a lo largo del trabajo de campo este otro debate, referente a cómo encarar una posible extinción de 1@s burr@s, tanto en este pueblo como a nivel global. Al respecto, por ejemplo, el arriero S. Torres considera que con su actividad están "preservando la especie del burro que hay en Mijas", habida cuenta del progresivo descenso del número de burros motivado por la mecanización del campo y de las poblaciones. La mayoría de burros en la actualidad se localizan en Galicia, Andalucía y Castilla-León, estimándose en no mucho más de 50.000 ejemplares el total del estado español, y quedando en Catalunya sólo en torno a un millar de individuos, "lo que sugiere el escasísimo aprovechamiento agropecuario del burro en las zonas más industrializadas (...); cifras irrisorias en comparación con los 1.300 .000 ejemplares de hace algo menos de siglo y medio" (Del Campo, 2012: 415).

La animalista L. de Diego defiende - ya que sostiene que los burros-taxi están maltratados - la necesidad de "sacar los burros de allí [de Mijas] y llevarlos al Refugio del Burrito o a otros santuarios en Cádiz, Madrid, Catalunya... Nosotros colocamos los burros para que lleven una vida en condiciones". Le pregunto si comparativamente considera que los perros también estarían mejor en un santuario específico, a lo que responde: "No, el perro necesita el contacto con el dueño (...) Mis perros prefieren estar conmigo, no prefieren estar en el campo o en la terraza".

Por otro lado, el animalista no-radical A. Paz disiente de lo anterior y defiende que "er trabaho le da la oportunidá de ke ze zigiera manteniendo er burro komo un animá balorao i ke no z’ehtinga”. El ecologista social J. Alarcón nos ha hablado, además, de la extinción de especies domésticas y sus variedades locales - cabras, ovejas, vacas, burrah, gallinas, etc. - por el abandono del socioecosistema campesino, algunas de las cuales van a quedar en refugios - ¿como un Arca de Noé?_, o como pieza de museo; ante lo que plantea otras alternativas: "O habría que buscar que volviera a ser salvaje [aquí en Miha], pero como en el planeta ya hay cada vez menos ecosistemas disponibles...”

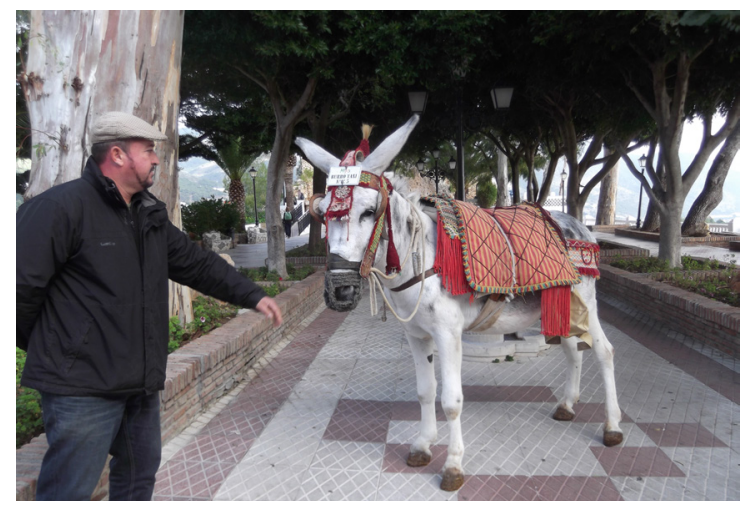

Foto 4: S. Torres y uno de sus burros.

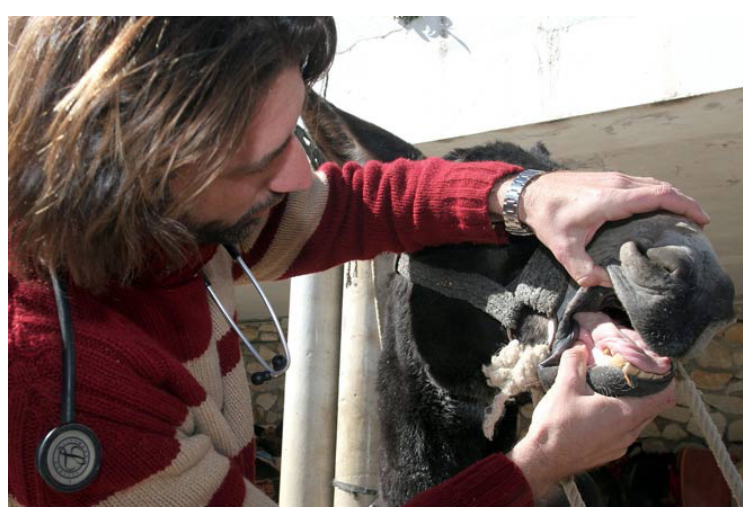

Veterinario examinando burros-taxi. 


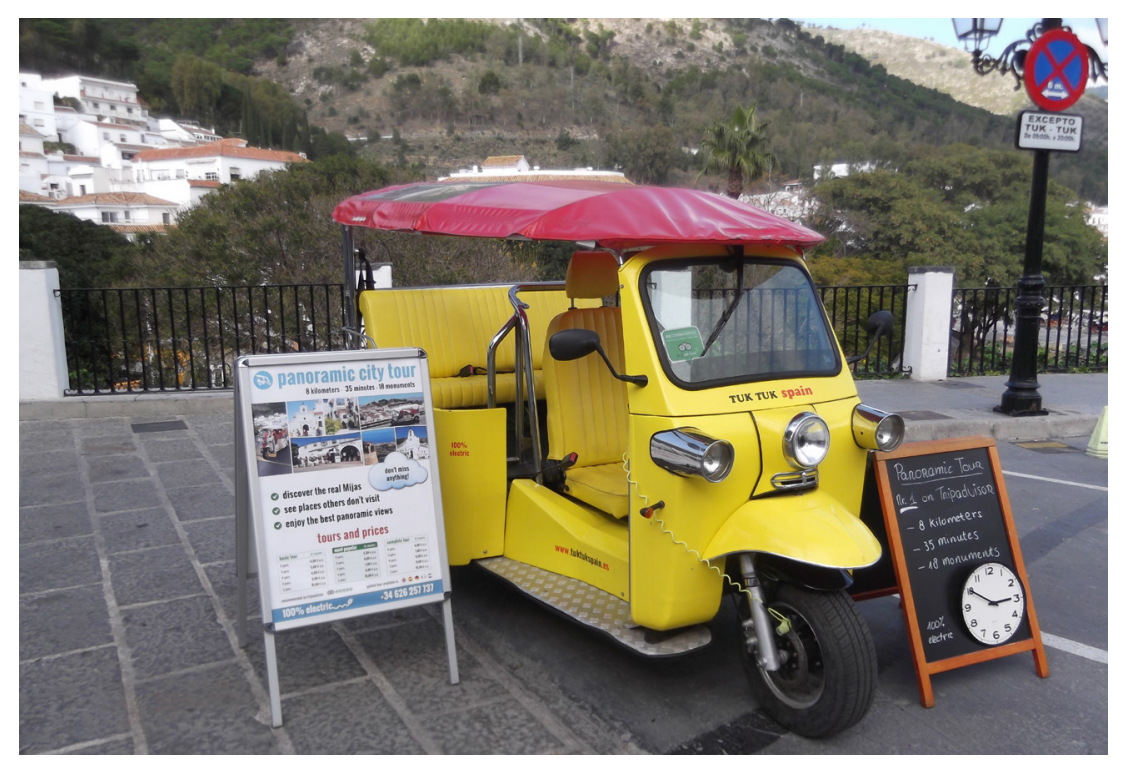

Tuk-tuk Spain "Panoramic City Tour”.

\subsection{Diversidad cultural vs. La Cultura}

Un nuevo-viejo debate interno de la filosofía y antropología nos sitúa, a nivel de los testimonios, en el contexto general de la vigente globalización occidental y sus efectos sobre la diversidad cultural, que rebrota intramuros de un mundo moderno que algunos han presupuesto - precipitada e interesadamente - ya "civilizado" u homogeneizado.

De ese modo, por ejemplo, ante la pregunta de qué opina de quienes están a favor de mantener la actividad de los burros-taxi L. de Diego señala: "Son gente que ha nacido así, que los han criado así; entiendo perfectamente que tengan esa condición, se han criado con eso, igual que los taurinos, igual que los toreros (...) Ellos no tienen la culpa. No vamos a insultarles ni nada”. Pretendo indagar más acerca del contraste de situaciones grupales preguntando a 1@s informantes antitaurin@s urban@s por qué creen que no lo perciben igual, indicando: "Quizás porque nosotros no lo concebimos como algo habitual, no lo hemos visto como algo normal en nuestro día a día (...) No es una cuestión de insensibilidad por parte de ellos ni por parte nuestra, simplemente es algo que han visto desde siempre" (J.L. Sánchez). También habíamos preguntado al veterinario de PACMA A. González si subirse en un burro no es ético, a lo que declara:

"Si no hay otro método alternativo [al trabajo de animales domésticos en otras sociedades], no nos parece mal, si los cuidan bien y les dan un trato ético, pero en España no es esa la situación (...) Pero si tienes un caballo, y lo tienes bien y sales a pasear, no estamos en contra de montar a caballo, pero si el caballo cuando no está siendo montado está encerrado, si tienes una parcela y el caballo está suelto y lo 
montas de vez en cuando, es como una mascota si la tienes todo el día atada tampoco estamos de acuerdo. Depende del trato que uno le dé, un trato ético y amigable".

\subsection{Ecologismo social vs. Animalismo}

Otro debate intrínseco a la polémica origen de esta investigación proviene desde sectores del movimiento ecologista, los cuales se desmarcan de algunas posturas de corte animalista. A este tenor, hemos encontrado un demoledor artículo del científico Javier Yanes en el que busca distanciar el ecologismo del pensamiento animalista radical:

"El animalismo, el de temperatura templada, es algo plenamente respetable, pero no es ecologismo, ni mucho menos ecología (...) En lo que respecta al animalismo febril, el que antepone la declaración de derechos del cangrejo a la conservación de los ecosistemas, en una sección de Ciencias el único enfoque válido podía ser el de denuncia... del animalismo (...) El movimiento ecologista moderno nació en la naturaleza y en la ciencia, llevando el medio ambiente a la cultura urbana a través de (...) pensadores y naturalistas con zapatos científicos que lograron colar el desajuste entre población, progreso y sostenibilidad ambiental (en términos actuales) en el debate político y social de los países desarrollados. En cambio, el movimiento contemporáneo por los derechos de los animales es un producto netamente urbano, impulsado desde ámbitos filosóficos y jurídicos, nacido de la humanización de las relaciones entre las personas y sus mascotas (...) Animalismo y ecologismo son cosas diferentes, causas diferentes con orígenes y fines diferentes, y a menudo mutuamente excluyentes, por mucho que se hayan mezclado en un mistificador batiburrillo debido, supongo, a varias causas (...)

Llegamos así al más allá del animalismo, mi favorito, donde este movimiento pierde toda su respetabilidad (...) un animalismo extremista caracterizado por la misantropía y la autoexculpación. Los extremistas del animalismo introducen el concepto de especismo o discriminación de especies, pero los criterios sobre a qué especies colocar al mismo nivel son, obviamente, de una subjetividad brutal. ¿Cuál es la frontera? ¿La capacidad de experimentar dolor, como algunos proponen? Los nociceptores, o receptores de dolor de las neuronas sensoriales, están presentes desde el ser humano hasta los invertebrados como los insectos (...) Al mismo tiempo, los animalistas extremos suelen abrazar opciones - como el veganismo-con las que se consideran autoexculpados de aquello que vilipendian, una actitud vana y pueril que comparten con cierto falso ecologismo (...) cada vez que se aborda la complicadísima relación del ser humano con la naturaleza, y en una constante acusación a todos los estúpidos que habitaron este mundo antes que ellos y que se equivocaron tanto para contribuir con su ensayo y error a que ellos, hoy, sean tan listos" (Yanes, 2014). 
Sin alcanzar los niveles retóricos de Yanes, algun@s de nuestr@s informantes han respondido de manera diversa a la cuestión de qué es el animalismo5: "Persona decidida a darle voz a los que no la tienen en la sociedad nuestra. Ser altavoz de esos animales" (J.L. Sánchez). "Animalismo es ser antiespecista" (A. González). "Soy animalista, pero no radical... También hay que entender lo que es un animal y hay que darle su lugar; no se puede tratar al perro como a una persona" (A. Paz). "Son personas de sensibilidad nueva, en general con educación media-alta urbana... tienen una relación diferente con los animales" (J. Alarcón).

Abundando en el debate desde posiciones ecologistas, el zoólogo miheño y militante F. Fernández - quien nos ha contado que su padre, Juan Fernández Cortés, era harriéro antiguo de Mijas- se muestra contrario a la abolición del servicio de burros-taxi, justificándolo fundamentalmente mediante el argumento ecologista de conservación de la biodiversidad. Eso sí, no duda en reivindicar mejoras en las condiciones de vida y trabajo de los equinos.

\title{
4.7. Trabajo animal (y humano) vs. Máquinas
}

\author{
"los animales no son para nuestro uso" (L. de Diego) \\ "eyoh trabahan pa mí, pero yo trabaho pa eyoh tambie" (S. Torres)
}

El último debate significativo que hemos entresacado de esta investigación ya se ha vislumbrado en apartados anteriores, y se circunscribe en la disyuntiva entre si mantener y aprovechar el trabajo animal - e incluso humano, por extensión — o si debiera sustituirse por maquinaria. Las personas animalistas 'radicales' consultadas plantean esta última opción. Así, por ejemplo, 1@s antitaurin@s proponen bicis, tren eléctrico y tuk-tuk como alternativa al burro-taxi: "En España, en pleno siglo XXI, con el desarrollo tecnológico que tenemos, habría que quitar los burros-taxi (...) La mejora tecnológica nos permitiría dejar el estilo de sociedad en la que vivimos... y también dejar de esclavizar a estos pobres animales" (J.L. Sánchez); apuesta que subraya el representante de PACMA, quien sostiene que se debe evolucionar "hacia un trato más ético a los animales, no utilizarlos como herramientas" (A. González).

Para el sector económico directamente implicado, sustituir los burros por máquinas provocaría que una veintena de familias miheñas se quedara sin trabajo (Harriéro 1), y ante la polémica propone que el Ayuntamiento debiera hacerse cargo del servicio

5. Para una comprensión más extensa y argumentada de los principios animalistas, sus debates internos, su historia y encaje en el conjunto del movimiento en pro de los derechos animales pueden consultarse las obras de P. Singer (1975), J. Mosterín (1995), J. Mosterín \& J. Riechmann (1995) y P. de Lora (2003). 
directamente y luego contratar a los arrieros. Harriéro $2 \mathrm{~S}$. Torres hace notar que ha disminuído la actividad del servicio de burros-taxi con las polémicas; asimismo, considera que "no se debería perder el burro-taxi para cambiarlo por un Tuk-tuk o por una bicicleta eléctrica de Taiwán. Una cosa es una cosa y otra cosa es otra cosa: esto es un pueblo típico andaluz".

En un estudio anterior habíamos realizado una entrevista al campesino miheño Salvador Porras Fernández, uno de los últimos gañaneh profesionales que todavía queda en activo en esta comarca de l'Argarbía, compitiendo con las máquinas y el avance del hormigón (vid. Porrah 2010b). Le preguntamos “¿por qué te dio por vivir de la ara i der kampo, $i$ bregà con animales?":

"Porque era lo que me gustaba y lo que me gusta. También le veía una mihiya’e koló, hoy se le ve menos color, pero entonces sí. Ganaba mi sueldo, y entonces no es como ahora, que había mucho trabajo (...) Es que yo araba to'r kampo'e Miha, entero. Ahora estoy yo sólo. Ya hay mu pokiyo trabaho, to z'ehtá perdiendo i ya naire labra; se están perdiendo los olivos, las higueras... Y pa no irme a la obra tenía que hacer algo. Porque lo que no quería era irme a trabahà a hohná.

['No future' pa la gañanería]: Ahkí namáh ke yo zuerte loh anterroyoh aí... aquí se acaba to. No es sólo hazè diarà, es tener los animales, tenel-loh enzeñaoh, y al primero al que hay que enseñar es al tío a bregà con los animales, porque hoy namáh que tienen behtiah en las cuadras y pa pazearze".

El animalista 'radical' converso a ecologista social, A. Paz, no se muestra partidario de relevar totalmente el trabajo animal y humano por las máquinas:

"Es verdad que los animales nos ayudan, y si buscamos un medio sostenible muchas veces es preferible un animal de trabajo que no un vehículo de combustible. [El problema de cambiar los animales por máquinas es también] porque somos como somos y sin duda esos burros se van a sacrificar en su mayoría (...) En Comares estaban pensando en sacrificar sus burros del campo porque ya no les eran útiles, pues los han reciclado [a algo parecido a burros-taxi] y les están dando una utilidad. Yo en ese aspecto no lo veo tan maltrato, porque nosotros entonces estamos maltratados, porque tenemos que trabajar (...) Tampoco olvidemos que lo eléctrico también conlleva una contaminación, plantearse que si centrales nucleares por la electricidad, o cortes de río por las presas...”

En el transcurso de la entrevista, J.L. Sánchez distingue entre la libertad o capacidad humana de decidir y la situación peculiar de los animales al surgir la cuestión del trabajo "esclavo" humano en empresas como la "Renta Básica" de Mijas ${ }^{6}$, puesto que en ese tipo de

6. En Mijas el Ayuntamiento utiliza el concepto 'renta básica' para referirse al trabajo temporal y 
"esclavitud" humana — someterse "voluntariamente" a condiciones laborales abusivas o indignas- “Tú estás eligiendo estar ahí, un animal nunca elige poder estar ahí, ninguno”. J. Alarcón, desde otra perspectiva, hace referencia a que en 1978 se declararon los Derechos de los Animales por la UNESCO, en cuyo artículo 7 se reconoce al animal que trabaja, pero... con unos derechos. Se plantea:

¿Por qué no abolir también el trabajo humano? ¿Por qué tenemos que utilizar un animal para trabajar? Porque si no lo hace un animal lo va a hacer una máquina, y si ese animal ya lleva miles de años jojo! haciendo un trabajo, el día que deje de hacerlo desaparece, eso está claro, porque nadie va a criar animales para tenerlos metidos en refugios. [Y considera que] es muy traumático querer romper de repente ese lazo cultural y afectivo con los burros (...) El animal no es libre, ninguno somos libres, ni siquiera los chimpancés en la selva o los indígenas, porque somos animales que vivimos en un complejo sistema social. El argumento de la libertad no sirve, es erróneo. Todo lo que reivindican ellos está muy bien (...) lo que no creo es eso de que no se puedan utilizar para transportar personas: es quitarle su derecho al trabajo, a esas relaciones hombre-animal".

\section{ALGUNAS CONCLUSIONES}

a) Las sociedades humanas están en continuo proceso de cambio, algunos de ellos imperceptibles. A veces los cambios se generan por agentes endógenos, a modo de catalizadores de influencias varias en una sociedad, pero cuando los agentes son primordialmente exógenos entendemos que más bien se trata de una aculturación, la cual puede tomar la forma de un conflicto entre culturas si se producen resistencias. La evolución cultural, de este modo, puede estar siendo dirigida hacia la finalidad que determine la sociedad más fuerte o hegemónica, a costa del universo simbólico y las prácticas de la sociedad, cultura o clase social más débil o minoritaria en ese conflicto. Creo que esta es la dinámica marco para entender qué está sucediendo con respecto a las sucesivas polémicas con el burro-taxi de Miha, es decir, un probable cambio cultural endógeno se está viendo condicionado por el choque abierto con la cultura urbanaoccidental-globalizante al generarse, como reacción al intrusismo foráneo, resistencias locales de cariz indigenista cuando, por ejemplo, aprecian una banalización exógena del concepto de maltrato por parte de los animalistas 'radicales'.

Esta diferente concepción cultural se aprecia, por ejemplo, en los distintos modelos de referencia al considerar genéricamente un animal, la primera imagen del significado de animal: las mascotas (con el perro como especie estrella, para los animalistas 'radicales' urbanos), los animales de trabajo (con lah behtiah como paradigma, para la

escasamente remunerado que llevan a cabo parad@s de larga duración en la empresa municipal Mijas Servicios Complementarios. 
concepción étnica andalomiheña "tradicional") y los animales brabíoh o silvestres (para una concepción mixta ecologista local). Algunos cambios puede que no lo sean tanto y finalmente puede que estemos hablando de procesos similares.

b) Por tanto, creemos estar ante un sociocentrismo (de urbe y clase social) apoyado en concepciones de etnocentrismo occidental que contempla el progreso tecnológico como un medio para el progreso moral. La determinación de lo que es inmoral en su viaje hacia lo que sería ético adopta a veces la forma de un paternalismo urbanita para con los miembros de la sociedad con cuyo universo cultural se choca o está en conflicto. A ese tenor hemos de tomar en consideración, una vez más, las perspectivas emic vs. etic - propia del grupo social $v s$. proyectada desde fuera- como unidades analíticas socioantropológicas que clarifican aspectos del choque cultural entre animalistas 'radicales' urbanos e 'indígenas' andalomiheños rurales, entre otros.

Recordemos, por ejemplo, el mayor aprecio histórico por los caballos entre las clases pudientes occidentales, parejo a su menosprecio de burr@s y mul@s de la clase campesina. También los detalles de la conversión del animalista urbano A. Paz al juntarse - praxiscon campesin@s: "Yo he aprendido con mi suegro en el campo muchas cosas que las veía aquí [en la ciudad] como horrorosas, y después vas allí y dices 'po, ¡koño!, no zon tan orrorozah"'. Así como el paternalismo sociocéntrico aculturizante que subyace en este discurso del animalista de PACMA A. González, cuando afirma que el problema con los arrieros "es que se han educado en un entorno que han utilizado el burro como herramienta, y hay que intentar reeducarlos. La sociedad va cambiando". Un cambio cuya finalidad parece obedecer, sin embargo, al ideal funcionalista de un mundo feliz desactivado de conflictos, incluso entre los propios animales, a quienes el informante A. González minusvaloraba la posible aplicación de las técnicas de vasectomía o ligadura de trompas como alternativas viables a la castración porque, aun así, "los burros se van a pelear".

c) Llegamos por esa vía a otra conclusión, la que contempla la utilización de un discurso finalista en la historia de los burros-taxi y de los animales de trabajo en general, considerando en dicho finalismo o teleología el rol del nuevo 'Dios Progreso' [tecnológico] como superador de las contradicciones y conflictos entre humanos y animales. Dicho finalismo en la historia de estos procesos supone una nueva antropización del devenir biológico del conjunto de la Tierra, que a su vez soslaya y olvida la modelación humana milenaria de los animales domésticos a nuestro alrededor —así como la de los mismos humanos en contacto con tales animales. Siguiendo al informante anterior, puesto que el rumbo de nuestra historia está predeterminado resultaría inútil resistirse a lo inevitable: "Tarde o temprano es algo que va a acabar. Estas cosas [carruseles con ponys, circos y espectáculos con animales, coches de caballos...] tienden a desaparecer en los países desarrollados del mundo, pues cuanto antes lo quitemos mucho mejor" (A. González). 
d) Gran parte de la sociedad miheña establecida en el pueblo aún mantiene rasgos y se siente parte del socioecosistema "rural" local, por la vinculación histórica del casco urbano tradicional con su amplio campo municipal. A pesar del aluvión poblacional heterogéneo de corte fundamentalmente urbanita y europeo implantado en su municipio las últimas décadas por la especulación urbanística y el desarrollismo desmedido, pervive en el imaginario colectivo de la minoría indígena andalomiheña ese nexo con el medio rural - sea real hoy en día o formando parte de las trayectorias vitales-, con los animales domésticos, con sus paisajes agrestes, con su sociabilidad propia, medio de vida, conocimientos agroganaderos, botánicos y forestales... unos rasgos socioculturales que han modelado y también resultan modelados por las influencias del entorno natural particular, según nos emplaza la perspectiva de la ecología cultural. De ese modo, la actividad del servicio de burros-taxi ha sido resultado de una reconversión laboral desde las actividades agroganaderas tradicionales del pueblo y campo miheños hacia la industria turística mediante el aprovechamiento efectivo de los conocimientos y saberes campesinos acumulados. Habida cuenta de que cada ciudad puede ser también contemplada como un socioecosistema específico (Berraquero, 2010), el choque de valores éticos entre los visitantes turistas urbanitas + los urbanitas circundantes a Mijas con el universo simbólico y la praxis arriera local parece evidente.

Esta suerte de "reserva indígena" que es Miha-pueblo en el contexto de la cosmopolita Costa del Sol explicaría el mantenimiento de algunas características en la unidad del socioecosistema rural local, puesto que no aparenta una separación real y efectiva —más evidente en sosioecosistemas urbanos- entre humanos, animales y el medio físico. La peculiar situación intersticial y liminal que se vive en Mijas se asemeja a esta reflexión del informante J. Alarcón: "La relación hombre-animal en las sociedades nuestras va cambiando, también porque tiene que cambiar, jlógico!, y tener unas relaciones con los animales diferente (...) porque la religión judeo-cristiana-islámica separa al hombre del animal". Y como ocurre a menudo cuando se persigue algo obsesivamente, la intencionalidad de separarnos de los animales parece querer ocultar el hecho efectivo y afectivo de dicha relación.

e) Y acerca del modo relacional con los demás animales, la ciencia de la etología aún tiene mucho que aportarnos. Deberíamos precisar, por ejemplo, qué es ciertamente maltrato en cada caso, y aclarar si existe consciencia de la castración-esterilización a la que algunos humanos someten a 1@s burr@s, perr@s, gat@s..., aclarar si conlleva deterioro psicológico del animal mamífero u otras consecuencias. Al respecto, cabría preguntarse -en términos propios del discurso animalista en su lucha contra el

7. Acerca de las implicaciones teóricas de los conceptos 'socioecosistema' y 'resiliencia socioecológica' véanse los trabajos de E. Ruiz y J.L. Solana (2012) y J. Escalera y E. Ruiz (2011), M. Maas (2011) y L. Berraquero (2010). 
'especismo'- si no supone un 'antropocentrismo' más (superioridad humana) erigirse en árbitro de la convivencia pacífica entre animales castrando a los machos para que no se peleen, proyectando categorías filosóficas y religiosas antropizadas hacia la diversa sociabilidad animal. Por otra parte, el avance de la etología quizás nos aporte un mayor conocimiento de las posibles diferencias entre animales silvestres y animales domésticos, habida cuenta que estos son animales de casa - domus - , criados en la compañía del ser humano, junto al cual tiene su habitual zona de confort, constituyendo a veces parte de su familia - con mayor o menor jerarquía relacional dependiendo de la especie y del ámbito rural o urbano. El asunto entonces sería ¿por qué hay que romper la relación del grupo doméstico interfaunístico si se produce en unas condiciones adecuadas? En dicha tesitura, la amplitud del conocimiento harriéro acerca de sus animales de trabajo se vería revalorizada.

f) En la deriva de estas conclusiones sólo nos resta apuntar lo conveniente de una mejora sustantiva de las condiciones laborales de los burros-taxi, tanto para el bienestar de los animales como para la subsistencia del oficio de sus dueños humanos. $\mathrm{Al}$ respecto, el representante de PACMA considera, de manera pragmática, lo siguiente: "Lógicamente nosotros pensamos que si pedimos que lo quiten, a lo mejor lo peor que conseguimos es que mejoren sus condiciones. Pero pedimos la abolición porque estamos seguros de que con el tiempo se va a acabar este tipo de actividades en la ciudad" (A. González). Desde su lado, el harriéro S. Torres aporta esta solución: "Unas cuadras municipales grandes, más adaptadas, con boxes y con espacio libre alrededor sería perfecto. Si me dieran unas instalaciones buenas er burriko no ehtaría amarrao".

En definitiva, considero que para evitar la extinción de las especies domésticas y razas locales, éstas han de tener un sentido o utilidad para el ser humano, que es quien las ha ido modelando a través de los siglos. Por ese motivo, la mejora sustantiva de las condiciones de trabajo y de vida de los burros-taxi y coches de caballos facilitaría un equilibrio para mantener su actividad y evitar su desaparición de nuestro lado en Miha, así como para mitigar esa pretendida y creciente fractura entre humanos y naturaleza. 


\section{BIBLIOGRAFÍA}

Ayuntamiento de Mijas (2011) Ordenanza municipal reguladora del servicio de burros taxis, burros-carros y coches de caballos del término municipal de Mijas.

Berraquero Díaz, Luis (2010) "Revisiones teóricas en torno a los conceptos de socioecosistema urbano y resiliencia socioecológica. Propuestas e implicaciones de la perspectiva ecosófica para el estudio de la metrópolis". En Repensando la metrópolis. Prácticas experimentales en torno a la construcción de nuevos derechos urbanos. Jornadas. 8 y 9 de Julio, 2010. Málaga. Sevilla: Centro de Estudios Andaluces. https://www. centrodeestudiosandaluces.es/actividades/comunicaciones/12779793701361625878 L4 Luis\%20Berraquero def.pdf (consultado el 11 de octubre de 2019)

De Lora, Pablo (2003) Justicia para los animales. La ética más allá de la humanidad. Madrid: Alianza.

Del Campo Tejedor, Alberto (2012): Tratado del burro y otras bestias. Una historia del simbolismo animal en Occidente. Sevilla: Aconcagua Libros.

Escalera Reyes, Javier y Ruiz Ballesteros, Esteban (2011) "Resiliencia socioecológica: aportaciones y retos desde la antropología”. Revista de Antropología Social, 20: 109-135.

Maass, Manuel (2011) “Socio-ecosistema”, en EnSuMA (Enciclopedia de la Sustentabilidad Mexicana y el Ambiente). http://132.248.203.25/EnSuMA/index.php/Socioecosistema\#Lecturas (Consultado el 11 de octubre de 2019)

Mosterín, Jesús (1995) Los derechos de los animales. Madrid: Debate.

Mosterín, Jesús y Riechmann, Jorge (1995) Animales y ciudadanos. Indagación sobre el lugar de los animales en la moral y el derecho de las sociedades industrializadas. Madrid: Talasa.

Porrah Blanko, Huan (2010a) "Normah Ortográfikah pa la Trahkrizión del Andalú (NOTA-Porrah 2009)". En Actas de la Va Hunta dehkritoreh en andalú (...) / Reunión de escritores-as en andaluz / 5th Meeting of Andalusian Writers. Er Paú / Padul (Graná / Granada), del 30 al 31 de octubre 2010, Sociedad para el Estudio del 'Andalú' (Z.E.A.), pp. 107-132.

(2010b): "Salvador Porras Fernández, el gañán de La Alcaría”. El Almiré. Revista social y cultural de Mijas, 14: 4

Ruiz Ballesteros, Esteban y Solana Ruiz, José Luis (eds.) (2012) Complejidad y Ciencias Sociales. Sevilla: Universidad Internacional de Andalucía.

Singer, Peter (1999) Liberación animal. Madrid: Trotta. 
Yanes, Javier (13 de mayo de 2014) "El ecologismo no debe caer en la trampa animalista". 20Minutos.es Blogs: Ciencias Mixtas, 13-mayo-2014. http://blogs.20minutos.es/cienciasmixtas/2014/05/13/el-ecologismo-no-debe-caer-en-la-trampa-animalista/ (Consultado el 11 de octubre de 2019) 